\title{
REVIEW
}

\section{Primary Care Review of Actinic Keratosis and Its Therapeutic Options: A Global Perspective}

Praven Chetty $\cdot$ Felix Choi $\cdot$ Timothy Mitchell

To view enhanced content go to www.dermtherapy-open.com

Received: September 25, 2014 / Published online: February 3, 2015

(C) The Author(s) 2015. This article is published with open access at Springerlink.com

\section{ABSTRACT}

Actinic keratosis (AK) is a common skin condition caused by long-term sun exposure that has the potential to progress to nonmelanoma skin cancers. The objective of this review is to examine the therapeutic options and management of AK globally, particularly in Australia, Canada, and the United Kingdom. Despite its potentially malignant nature, general awareness of $\mathrm{AK}$ is low, both in the general population and in the primary health care setting, especially in countries with low incidence. There is no standard therapeutic strategy for $\mathrm{AK}$; it is treated

Electronic supplementary material The online version of this article (doi:10.1007/s13555-015-0070-9) contains supplementary material, which is available to authorized users.

P. Chetty $(\bowtie)$

Beach Avenue Medical Clinic, Peachland, BC,

Canada

e-mail: drpchetty@gmail.com

F. Choi

Balgowlah Skin Cancer Clinic, Balgowlah, NSW, Australia

T. Mitchell

Montpelier Health Centre, Bath Buildings,

Montpelier, Bristol, UK through a variety of lesion-directed or fielddirected therapies or a combination of both. A variety of treatment options are used depending on the experience of the primary care physician, the pathology of the lesion, and patient factors. Studies have shown that the physicians do not always use the optimal treatment option because of a lack of knowledge. The higher incidence of $\mathrm{AK}$ in fair-skinned people in Australia has resulted in well-established management strategies and guidelines for its treatment, compared with countries with lower incidence. It is essential to raise the awareness of $\mathrm{AK}$ because of its potential to progress to invasive squamous cell carcinoma. Primary care physicians are often the first to see this condition in their patients and are perfectly placed to educate the public and raise awareness. It is therefore desirable that their education and knowledge about $\mathrm{AK}$ and its treatment are up to date.

Keywords: Actinic keratosis; Awareness; Field directed; Lesion directed; Non-melanoma skin cancer; Primary care; Squamous cell carcinoma; Topical treatment 


\section{INTRODUCTION}

Actinic keratosis (AK) is a common skin disease caused by long-term sun exposure [1], and typically forms on the face, neck, balding scalp, chest, shoulders, and the back of arms and hands of adults [2]; $75 \%$ of all reported lesions present on the head, neck, and forearms [3]. AK is characterized by the formation of keratotic macules, papules, or plaques with superficial scales on a red base, which are classified based on histological features (Table 1). Lesions are often asymptomatic, but they can be sore or itchy [4]. Due to the cumulative nature of the condition, the incidence of $\mathrm{AK}$ increases with age and is a common condition in the adult population aged over 50 years [2].

Some AK lesions can undergo malignant transformation and progress to invasive squamous cell carcinoma (SCC) [5]. However, despite its seriousness, public awareness of this potential complication is generally poor. Treatment of AKs depends on the clinical presentation of the lesions: it may be targeted at specific lesions (lesion directed) or at multiple lesions over a large area (field directed), and sometimes both treatment approaches are combined. A number of treatment options are available for AK, although no universal standard has yet been established. Therapy options include cryosurgery, curettage, excision surgery, photodynamic therapy (PDT), and topical treatments (5-fluorouracil [5-FU] cream, diclofenac gel, imiquimod cream, and ingenol mebutate gel).

This review examines the awareness of $\mathrm{AK}$ among primary care physicians and the public, current therapeutic options and strategies, and comparison of the prevalence and management of AK around the world, especially Australia, Canada, and the United Kingdom (UK). The analysis in this article is based on previously conducted studies, and does not involve any new studies of human or animal subjects performed by any of the authors.

\section{DISEASE AWARENESS}

\section{Prevalence}

$\mathrm{AK}$ is a global condition and its prevalence is significant; for example, it is the second most common diagnosis made by dermatologists in the USA [1]. Recent reports have indicated an increase in $A K$ rates $[6,7]$. This is partly due to environmental factors, such as thinning of the ozone layer and more ultraviolet (UV) radiation reaching the Earth's surface [8], and partly to lifestyle factors such as increased tanning (outside and sunbed) [9]. The prevalence rates are highest in countries that have high sun exposure and have a large fair-skinned population (Fitzpatrick skin type I and II).

It is not surprising therefore that the highest AK prevalence rate has been documented in Australia-over $40 \%$ in individuals aged over 40 years [10]. This rate is exacerbated by the much thinner layer of ozone above this country. In contrast, countries with low levels of sun exposure, such as the UK and Ireland, report much lower rates of 19-25\%, in individuals aged over 60 years [11]. Similar rates have been reported in the USA and Europe: $11-26 \%$ and $11-25 \%$, respectively $[12,13]$. It would therefore be advisable for areas with high levels of sun exposure to incorporate a skin examination as part of patients' annual check-up.

\section{Risk Factors}

The prevalence of AK is strongly linked to fair skin, advanced age, and gender. A study in England reported a prevalence rate of $15.4 \%$ 
Table 1 Classification of actinic keratosis based on histologic features

\begin{tabular}{|c|c|}
\hline Variant & Characteristics \\
\hline \multirow[t]{4}{*}{ Hypertrophic } & $\begin{array}{l}\text { Pronounced hyperkeratosis with areas of } \\
\text { parakeratosis }\end{array}$ \\
\hline & Thickened epidermis \\
\hline & Irregular downward proliferation \\
\hline & $\begin{array}{l}\text { Keratinocytes in stratum malpighii (may } \\
\text { show loss of polarity and pleomorphism) }\end{array}$ \\
\hline \multirow[t]{3}{*}{ Atrophic } & $\begin{array}{l}\text { Generally atrophic epidermis with slight } \\
\text { hyperkeratosis }\end{array}$ \\
\hline & $\begin{array}{l}\text { Basal layer shows cells with } \\
\text { hyperchromatic nuclei }\end{array}$ \\
\hline & $\begin{array}{l}\text { Cells may proliferate towards dermis as } \\
\text { buds or duct-like structures }\end{array}$ \\
\hline \multirow[t]{2}{*}{ Bowenoid } & $\begin{array}{l}\text { Difficult to distinguish from Bowen } \\
\text { disease }\end{array}$ \\
\hline & Full thickness atypia present \\
\hline Acantholytic & $\begin{array}{l}\text { Intercellular clefts present as result of } \\
\text { anaplastic changes in base of epidermis } \\
\text { that produce dyskeratotic cells with } \\
\text { disrupted cellular bridges }\end{array}$ \\
\hline Epidermolytic & $\begin{array}{l}\text { Granular degeneration or epidermolytic } \\
\text { hyperkeratosis }\end{array}$ \\
\hline Lichenoid & $\begin{array}{l}\text { Dense dermal infiltrate of lymphocytes in } \\
\text { papillary dermis that damages epidermis } \\
\text { basal layer }\end{array}$ \\
\hline \multirow[t]{2}{*}{ Pigmented } & $\begin{array}{l}\text { Excessive amounts of melanin in basal } \\
\text { epidermis }\end{array}$ \\
\hline & $\begin{array}{l}\text { Numerous melanophages in superficial } \\
\text { dermis }\end{array}$ \\
\hline
\end{tabular}

Reproduced with permission from Rosen et al. [7]

and $5.9 \%$ in men and women, respectively. This rate increased to $34.1 \%$ and $18.2 \%$ in men and women aged above 70 years [14]. The study found the incidence of $\mathrm{AK}$ was greater in individuals with red hair and freckles, which indicates Fitzpatrick skin type I. There was a similar, but more pronounced, increase reported in Australia; prevalence rates of $\mathrm{AK}$ were $22 \%$ and $8 \%$ for men and women aged $30-39$ years, which increased to $83 \%$ and $64 \%$, respectively, in adults aged 60-69 years [15]. One reason for the greater occurrence rate in males could be they are more likely to work outdoors and receive more cumulative sun exposure.

\section{Poor Awareness}

Despite the high prevalence of AK, awareness of the disease and its relationship with SCC is generally poor [16]. In a telephone survey of 1,500 Europeans aged 40-70 years, only 6\% were aware of AK [17]. Similarly, when 2,100 physicians from seven countries (USA, Australia, UK, Italy, France, Germany, and Spain) were surveyed about their awareness of non-melanoma skin cancer and $\mathrm{AK}$, results showed that primary care physicians were more familiar with basal cell carcinoma (90\%) than with AK (74\%) [18]. Of the primary care physicians who were aware of AK, only $40 \%$ had treated the condition [18]. Over 700,000 new cases of SCC are diagnosed every year in the USA. Nevertheless, SCC is excluded from national cancer registries in the USA, making accurate prevalence rates, along with resulting metastases and deaths, difficult to estimate [16].

The potential for malignant transformation is a reason for concern about the poor public awareness of AK. Intraepidermal proliferation of atypical keratinocytes can be seen on AK lesions, and studies have shown that up to $16 \%$ of AKs progress to invasive SCCs [5]. One reason for the low level of $\mathrm{AK}$ awareness is the wide range of variations in its clinical presentation (Fig. 1), which include the cutaneous horn, the pink and pearly lichenoid AK, pigmented AK, and actinic cheilitis [4]. The clinical variants of AKs are shown in Fig. 2. 

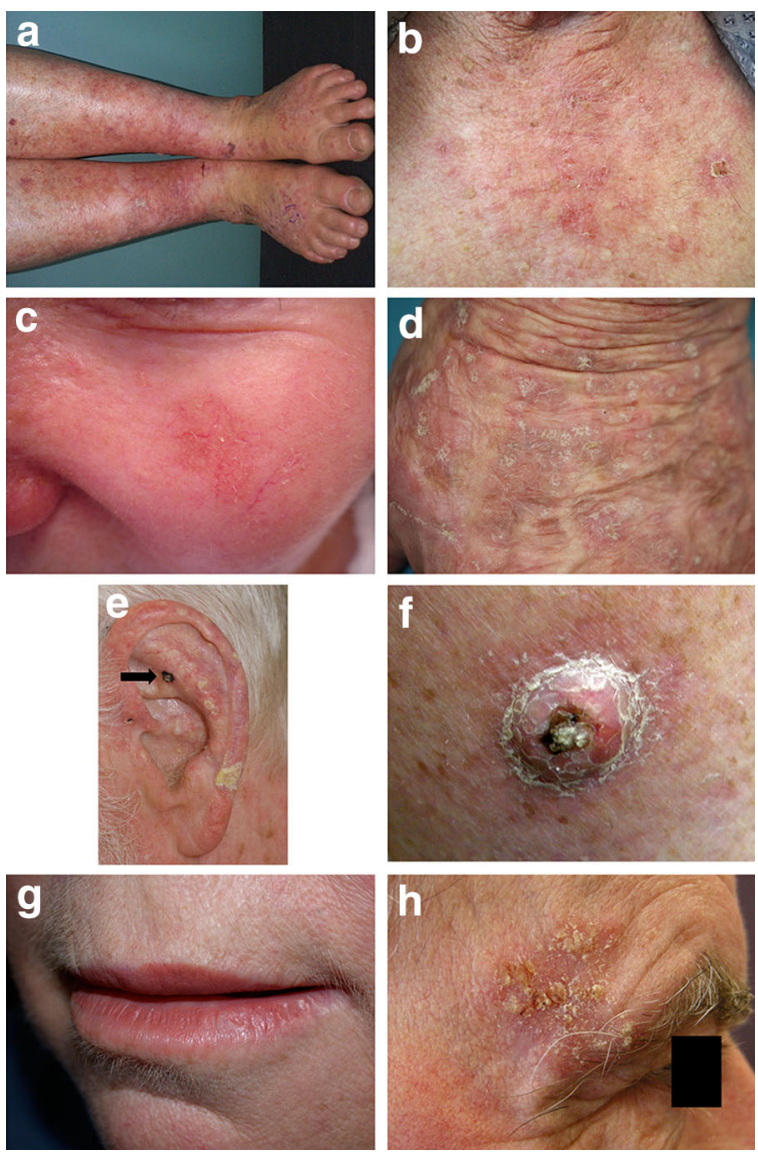

Fig. 1 Signs and symptoms of AKs. a Sun-damaged skin: severe sun damage on lower legs due to chronic exposure to $\mathrm{UV}$; an increased risk of developing AKs is expected. b Scaly and crusted patches on sun-damaged skin, an AK can usually be felt before it is seen. c Rough, reddish, raised bumps: most AKs look like raised, scaly, red bumps on the skin. d Thick, discolored, scaly and crusted skin with many growths: skin that has accumulated years of sun damage, such as the scalp, face, and arms can have many AKs. e Pigmented AK: the AKs on this man's face appear as pigmented skin or as brown patches. When AKs look like this, they can resemble melanoma. f Cutaneous horn: some AKs grow quickly and look like an animal's horn. Horns are more likely to progress to skin cancer; illustrated is a squamous cell carcinoma (keratoacanthoma). g Whitish scale on bottom lip: when an AK forms on the lip, the AK is called actinic cheilitis. If the patient has a rough scaly lip, splitting lips, or lips that always feel dry, they should see a dermatologist. $\mathbf{h}$ Squamous cell carcinoma on right temple: without treatment, some AKs progress to squamous cell carcinoma. $A K$ Actinic keratosis. Images are published with permission from the New Zealand Dermatological Society Incorporated
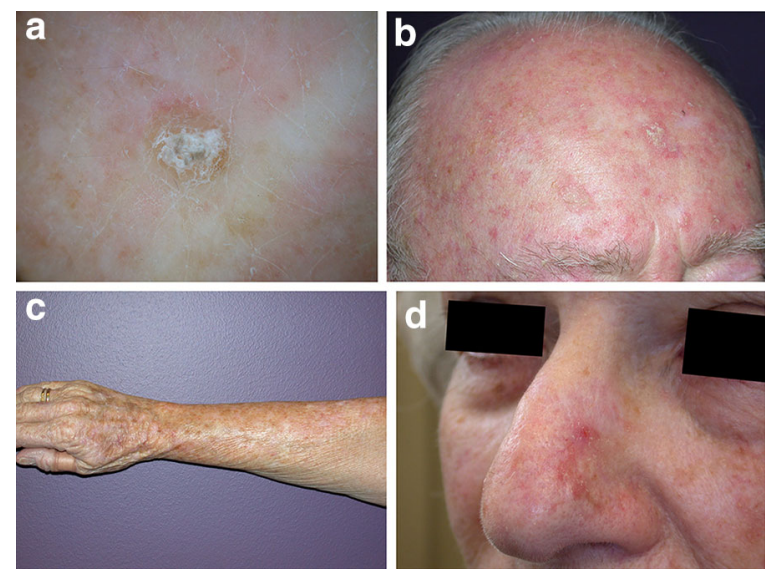

Fig. 2 Clinical variants of AKs. a Hyperkeratotic AK. b AK with field change (forehead and partial scalp). c Classical AK (milder degree of field change on the arm). d AK with adjacent hyperpigmented areas. $A K$ Actinic keratosis. Images are published with permission from the New Zealand Dermatological Society Incorporated

\section{The Burden of AK}

The burden and cost of AK on the patient and society is also underestimated. In 2005, the Society of Investigative Dermatology and the American Academy of Dermatology estimated that AK affected more than 58 million people in the USA [19]. Furthermore, direct costs relating to AK were considerable: $\$ 1.2$ billion in 2004, with $92 \%$ of these costs due to physician office visits and 5\% to prescription drugs [19].

For patients, the burden can be both personal and financial. Patients with AK experience impairment to their quality of life in terms of physical symptoms such as itching, burning, tenderness, and dyspigmentation [19, 20]. Psychological impairment has also been reported, impacting on the patients' confidence and their sense of well-being [20]. There is no inpatient hospital stay associated with a primary diagnosis of AK. However, the costs of services and treatment, and physician time to the patient, can be expensive, if they are not reimbursable [19]. 


\section{THERAPEUTIC OPTIONS AND DISEASE MANAGEMENT}

A substantial proportion of skin cancers are preventable. Therefore, an important first step is education for the use of sunscreens, which have been shown to reduce AKs and SCC [21-23]. However, the current prevalence of AKs demonstrates that prevention alone is not sufficient.

Treatment of AKs is always recommended, as there are no reliable clinical predictors to distinguish an AK lesion from those that will become malignant and transform into SCC [11, 20]. If untreated, SCC can become locally invasive, leading to metastases and death.

Treatments for AK fall into two categories: Lesion directed or field directed. Both may also be combined sequentially. The optimal treatment is determined by the pathology of the AK lesion and patient considerations. The most common therapy options for AK are described in Table 2.

\section{Lesion-Directed Treatments}

Lesion-directed treatments commonly involve focal ablative procedures [24]. Cryosurgery, with the use of liquid nitrogen, is a standard first-line approach for the treatment of discrete lesions that can be carried out in a primary care setting. It is a rapid, low-cost approach [24, 25], and a 2- to 5-s freeze is reported to remove around $70 \%$ of AKs treated [26]. Response to treatment appears to be related to the length of the freeze time [25]. Side effects associated with cryosurgery include pain, redness, edema, blistering, and hypopigmentation [24, 27].

Laser therapy is another lesion-directed treatment, but is a higher cost option to cryosurgery and requires more specialized training. The associated side effects include pain, inflammation, pigment changes, and delayed healing. Curettage and excisional surgery can be an effective approach for some lesions, particularly hyperkeratotic lesions and/ or where histological information is required (e.g., resistant lesions or to check for an occult SCC) [24]. However, local anesthetic is necessary and the procedure can result in pain, bleeding, and scarring.

\section{Field-Directed Treatments}

\section{5-FU}

5-FU 5\% cream has been used as a topical approach for the treatment of AKs for many years $[25,26]$. The cream is applied twice daily for up to 4-6 weeks [25] and clearance rates of $50 \%$ have been reported [24]. However, treatment with 5-FU cream can result in severe dermatitis, sometimes accompanied by wound infections, pruritus, pain, and ulceration, with scarring lasting throughout the duration of the treatment [28]. The inflammation induced can be so severe that patients stop before adequate treatment has been received and the photosensitivity reaction also limits its use in the summer.

\section{Diclofenac}

Diclofenac 3\% gel, used twice daily for 90 days, is associated with complete response rates of $34-47 \%$ of patients [29]. Diclofenac is generally well tolerated; side effects include pruritus, erythema, and dry skin [24]. Australian guidelines suggest the use of diclofenac in combination with cryosurgery for hypertrophic or resistant AKs [25]. As a nonsteroidal anti-inflammatory drug, diclofenac may cause photosensitivity reactions in rare cases that are usually attributed to UV radiation [30]; however, contact dermatitis is a more common side effect [31]. 
Table 2 Summary of treatment options for AK [24]

\begin{tabular}{|c|c|c|c|}
\hline Treatment & Response & Recurrence $^{\mathrm{a}}$ & Side effects \\
\hline \multicolumn{4}{|l|}{ Lesion-directed treatment } \\
\hline Cryosurgery (liquid nitrogen) & $75-98 \%$ & $1.2-50 \%$ & $\begin{array}{l}\text { Pain, redness, edema, blistering, scarring, } \\
\text { hypopigmentation }\end{array}$ \\
\hline Laser therapy & $\sim 90 \%$ & $10-15 \%$ & $\begin{array}{l}\text { Pain, inflammation, pigment changes, } \\
\text { scarring, delayed healing, erythema }\end{array}$ \\
\hline Curettage/excision/shave biopsy & Undocumented & Undocumented & Pain, bleeding, scarring \\
\hline \multicolumn{4}{|l|}{ Field-directed therapy } \\
\hline Ingenol mebutate & $34.1-42.2 \%^{b}$ & $44.6-67.6 \%{ }^{b}$ & Erythema, flaking, scaling, crusting \\
\hline Topical 5-FU & $50 \%$ & $55 \%$ & $\begin{array}{l}\text { Severe dermatitis, wound infections, } \\
\text { pruritus, pain, ulceration, scarring }\end{array}$ \\
\hline Chemical peeling & $\sim 75 \%$ & $25-35 \%$ & Pain, inflammation, pigment changes, scarring \\
\hline Diclofenac 3\% gel & $50-79 \%$ & Undocumented & Pruritus, erythema, dry skin \\
\hline Topical photodynamic therapy & $70-90 \%{ }^{\mathrm{c}}$ & Undocumented & $\begin{array}{l}\text { Application-site pain, photosensitivity, } \\
\text { post-treatment inflammation }\end{array}$ \\
\hline Imiquimod 5\% & $55-84 \%$ & $10 \%$ & $\begin{array}{l}\text { Erythema, itching, burning sensation, } \\
\text { fatigue, nausea, influenza-like } \\
\text { symptoms, myalgia }\end{array}$ \\
\hline Sun protection & NA & NA & NA \\
\hline $\begin{array}{l}\text { Adapted with permission from Stc } \\
\text { 5-FU 5-fluorouracil, } A K \text { actinic ke } \\
\text { a One-year recurrence } \\
\text { b LEO: SMPC, ingenol mebutate } \\
\text { c Response rates enhanced by cur }\end{array}$ & $\begin{array}{l}\text { kfleth et al. [24], } \\
\text { atosis, } N A \text { not ap }\end{array}$ & $\begin{array}{l}\text { able } 1 \\
\text { icable }\end{array}$ & \\
\hline
\end{tabular}

\section{Imiquimod}

In Australia, the approved indication for imiquimod is once daily, three times per week, for up to 16 weeks. However, in practice, most clinicians recommend applying it two to three times a week for two 4-week cycles [25]. If necessary, cycles may be repeated after a month. Complete clearance rates of $44-46 \%$ have been reported [32]. Side effects associated with imiquimod include erythema, itching, and a burning sensation [24]. Systemic side effects of imiquimod include headache, fatigue, nausea, influenza-like symptoms, and myalgia [33].
The beneficial effect of use of cryosurgery followed by field treatment with imiquimod $3.75 \%$ cream has been shown [34]. Median total $\mathrm{AK}$ reductions of $86.5 \%$ were achieved with imiquimod compared with $50 \%$ for vehicle, with complete clearance rates of $30.2 \%$ and $3.3 \%$, respectively.

\section{Ingenol Mebutate}

Ingenol mebutate gel is a recent addition to topical treatments for non-hyperkeratotic, nonhypertrophic AK in adults. Ingenol mebutate appears to have a dual mechanism of action; it 
preferentially causes cell death in transformed keratinocytes and induces an inflammatory reaction that kills the remaining cancerous cells [35]. It is approved for the treatment of AKs located on the face, scalp, trunk, and extremities. It was approved by the US Food and Drug Administration (FDA) for AK in January 2012 as a 2- or 3-day course of therapy; it is also approved in Europe, Australia, Canada, and other countries. In a pooled analysis of trials on the face and scalp, a complete clearance rate of lesions of $42 \%$ and lesion reduction rate of $83 \%$ were reported at day 57 [36]; at 12 months a sustained clearance rate of $46 \%$ and lesion reduction rate of $87 \%$ were achieved [37]. Adherence to treatment was $>98 \%$. As with all topical treatments, local skin responses include erythema, flaking, scaling, and crusting [35]. Ingenol mebutate does not exhibit any phototoxic or photosensitizing properties and can therefore be used throughout the year [38].

A beneficial effect on $\mathrm{AK}$ treatment of ingenol mebutate following cryosurgery compared with cryosurgery alone has been reported [39, 40]. Treatment with ingenol mebutate $0.015 \%$ gel for 3 consecutive days, 3 weeks after cryosurgery resulted in higher complete clearance rates than vehicle at both 11-week rates $(60.5 \%$ vs. $49.4 \%)$ [39] and 12 months (30.5\% vs. 18.5\%) [40]. Complete clearance was sustained at 12 months with greater reduction of AKs compared with vehicle $(68.2 \%$ vs. $54.1 \%)$ and fewer patients experiencing the emergence of new lesions $[39,40]$.

\section{PDT}

PDT, using the photosensitizing cream methyl aminolevulinate, is another effective topical treatment option for AKs. The cream is applied to the affected area and left for $3 \mathrm{~h}$ before a 7-9-min illumination of the area is carried out, usually in a specialized clinic. A single PDT treatment is sometimes sufficient, although multiple numbers are used [25]. Efficacy rates of $70-90 \%$ have been reported [24]. Side effects associated with PDT include intense application-site pain that requires management and hypersensitivity to daylight. There is a degree of post-treatment inflammation, which usually subsides within a week [26].

\section{Lesion Characteristics Determining Treatment}

Lesion-directed treatment is usually a first-line approach for isolated lesions; a field-directed approach is used when there are multiple lesions present [24]. In some cases, fielddirected therapy is combined with cryosurgery. As lesion-directed treatment fails to take into account potential damage to the surrounding skin, field-directed treatment may be the more effective way of eradicating both evident and subclinical lesions [24]. This may prevent the potential development of invasive SCC.

The anatomic location of $\mathrm{AK}$ lesions is a significant factor in the choice of the most appropriate treatment approach. Pharmacologic field-directed therapy is ideal for cosmetically sensitive or difficult to treat locations such as the face, chest, back of the hands, arms, and lower legs [24, 41]. The area around the eyes and mouth requires the use of a treatment with a minimal skin-irritating effect [11]. The hyperkeratotic surface of the backs of the hands requires multiple, extended treatments or pre-treatment with $5 \%$ salicylic acid [11]. Lesions below the knee have a propensity for ulceration and poor healing, will require close monitoring and may require elevation of the leg and compression bandaging. 
The grade of the lesion affects the treatment response. Lower-grade lesions are generally more responsive than higher-grade lesions [41], and consequently an important consideration for treatment.

\section{Patient Factors for Treatment}

Patients' willingness to seek diagnosis and treatment depends primarily on their attitude towards $\mathrm{AK}$ as a potentially malignant lesion. Young patients view skin cancer as a problem of adulthood, whereas adults think that their general self-assessment of good health limits their susceptibility to skin cancer [42]. Moreover, the desire for a suntanned appearance and the erroneous belief that a suntan is protective against skin damage contributes to inadequate use of sunprotection behaviors [42].

For treatment strategies to succeed, physicians and patients need to agree on a treatment plan that is understood by the patient to promote high adherence. For the physician, treatment choice will depend on disease-related factors: the patient profile (e.g., existing comorbidities); the cost of treatment; and patient preference. Understandably, both patients and physicians wish to combine high efficacy with minimal side effects. This is one reason why 5 -FU cream, with its significant side effects, is less often used [24]. In addition, the photosensitizing effects of some topical agents, such as 5-FU, will discourage some patients from selecting this approach. Nonetheless, it should be noted that patient tolerance of side effects can vary and depend on factors such as age, physical health, and presence of comorbidities. Consequently, it is imperative that patients are informed about the efficacy and side effects of the available treatments. The cosmetic effects of the treatment are also an important consideration for some patients, as the side effects can be very pronounced and visually obvious and consequently result in psychosocial difficulties (Fig. 3) [43]. Therefore, treatment choice for patients depends both on the cost of the treatment and the length of its side effects.

Pharmacologic therapy is a good choice for patients who understand and demonstrate high personal responsibility, as well as understand the risks of $\mathrm{AK}$ and the need for good adherence to treatment, as this treatment option can be undertaken conveniently in their home [20]. It is speculated that there is a lower rate of treatment adherence with an agent that requires repeat application over a prolonged period of time, compared with a topical agent with short treatment duration such as ingenol mebutate [36]; however, comparative studies have not been conducted [41]. For example, imiquimod treatment duration can range 4-16 weeks, and is administered 2-3 times weekly. In addition, diclofenac in hyaluronic acid is used twice a day for 3 months, leading to adherence issues as well as financial costs. Other strategies that are likely to improve adherence are a good doctor-patient relationship, and patient education and follow-up by telephone or visits [41].
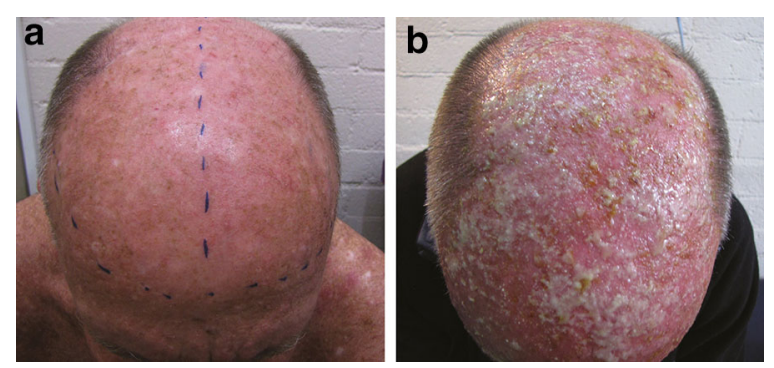

Fig. 3 Pustulation in a patient with marked AK a pre-treated with retinoic acid and $\mathbf{b}$ followed by methyl aminolevulinate photodynamic therapy. $A K$ Actinic keratosis. Reproduced with permission from Tran and Salmon [43] 
Cryosurgery and PDT are alternative treatment options for patients who are not suitable for pharmacologic field-directed therapy, given their age, medical comorbidities, or compromised cognition. The main advantages of these procedures are their speed and adequate clearance of abnormal tissue. However, targeted approaches fail to address field cancerization. In addition, there are treatment-associated side effects such as scarring and hypopigmentation for cryosurgery; and application-site pain and photosensitivity for PDT.

\section{COMPARISON OF GLOBAL PRIMARY CARE MANAGEMENT OF AK}

\section{Influence of Prevalence}

The prevalence of $\mathrm{AK}$ is high in Australia because of its large proportion of fair-skinned people and higher sun exposure compared with Canada and the UK. The latitude gradient within Australia results in a larger occurrence of $\mathrm{AK}$ in lower latitude regions such as Queensland compared with other parts of Australia; there is also a greater incidence of AK in rural areas where jobs involve greater sun exposure [25].

The higher prevalence of AK in Australia has resulted in a greater awareness of AK for both patient and physician than in countries with lower prevalence [18]. Consequently, management of AKs in Australia is very comprehensive; there are established management strategies and detailed clinical practice guidelines written by the Cancer Council of Australia, although these are now several years old and do not describe treatments that have become available more recently [25].
Given their higher familiarity with $\mathrm{AK}$, Australian primary care physicians are more likely to treat the condition themselves than refer on to other specialists (44\% for Australia vs. $91 \%$ for UK) [18]. With the aging population and the subsequent rise in numbers of patients with $\mathrm{AK}$, this may provide challenges to secondary care systems in countries where primary care physicians are less familiar with diagnosing the condition, underlining the continuing need for education about $\mathrm{AK}$ in this setting.

\section{Treatment Trends}

\section{Current Treatments}

A 2006 retrospective study of Australian general practitioners' medical records reported that the most commonly used treatments for AK lesions were cryosurgery (63\%), excision (18\%), and a mixture of excision, curettage, and cryosurgery (5\%) [44]. Topical agents (4\%) were not commonly employed, although a new product, ingenol mebutate gel, which was developed in Australia, is now being used [26] as well as 5-FU, imiquimod cream, and diclofenac gel [25]. One reason for the low use of topical agents could be that the resultant therapeutic response can be unpredictable. Another more practical reason is that invasive treatment options are eligible for government rebate, whereas this is not necessarily the case with topical treatments [44].

There are no recent treatment guidelines for Canada; however, a comprehensive five-step approach strategy for the treatment of AK has been proposed (Fig. 4) [20]. This strategy proposes: (1) periodic dermatologic examinations; (2) field-directed therapy; (3) lesion-directed therapy; (4) patient education with regard to sun protection and the importance of AK treatment and its 


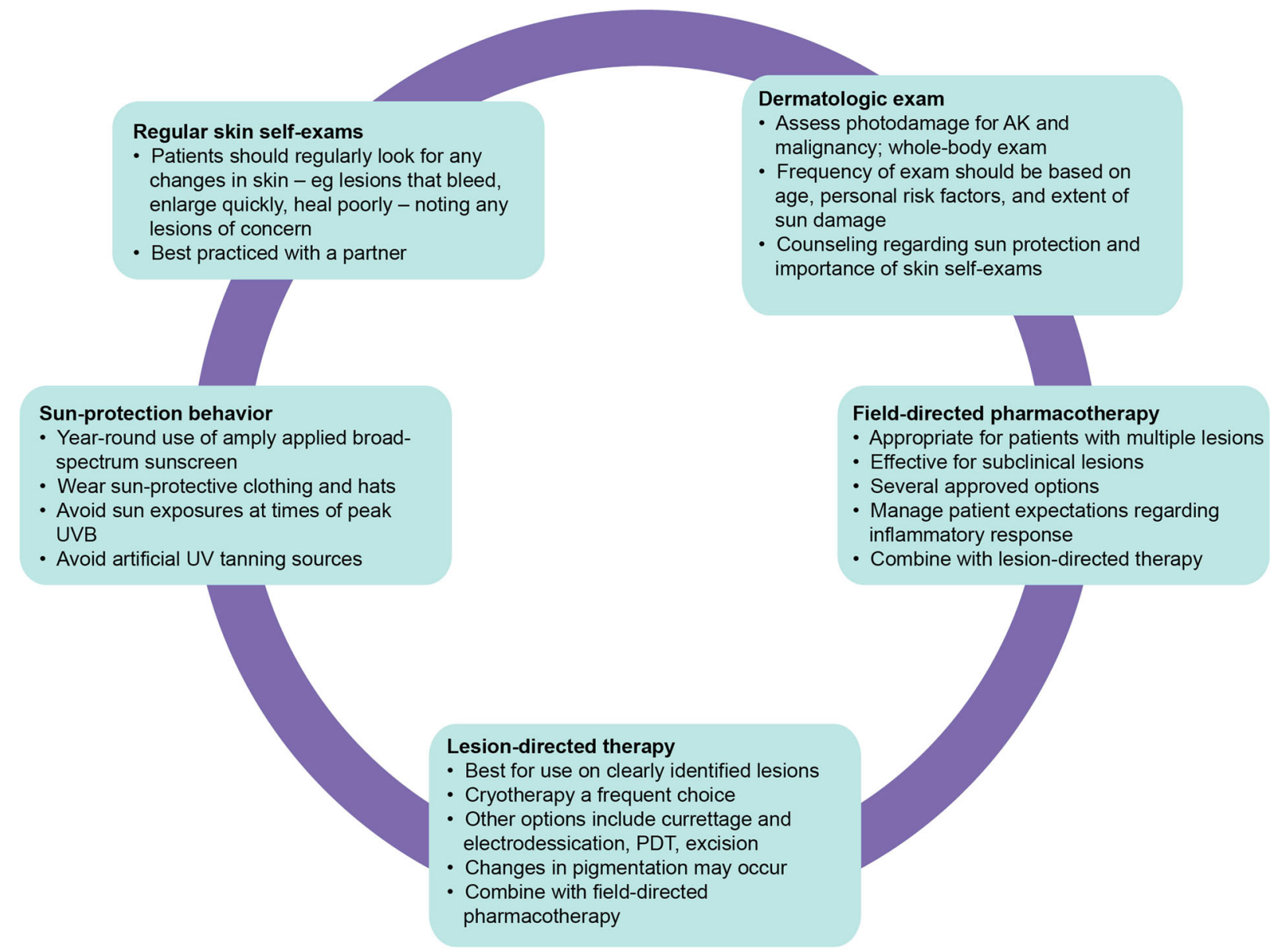

Fig. 4 Multistep approach for evaluation and treatment of AK and photodamaged skin. AK Actinic keratosis, PDT photodynamic therapy, $U V$ ultraviolet. Reproduced with permission from Ceilley and Jorizzo [20]

completion; and (5) regular skin self-exams. The choice of therapy is a decision that combines both the characteristics of the AK lesion and patient considerations (Table 3).

In Europe, a simple treatment algorithm to assist clinicians in the management of $\mathrm{AK}$ and to standardize and improve patient care was developed in 2008 by the European Skin Academy [24]. An update of these guidelines by the European Dermatology Forum indicated that there is a paucity of studies on the frequency and cost of AK treatment in Europe [28]. Clinical guidelines from the UK Primary Care Dermatology Society state that patients should be managed in the community if at all possible, and only referred to a consultant dermatologist in cases of diagnostic uncertainty or if the damage is widespread or severe [45]. These guidelines recommend both individual lesion treatment for few or widely spread lesions and field therapy for areas of skin with multiple AKs (Fig. 5). Cryosurgery is generally widely utilized within Europe and is an effective treatment for single AKs [24]. Alternative, non-invasive topical treatments such as imiquimod, PDT, diclofenac 3\% gel, and ingenol mebutate gel are seen as promising options for treating larger areas of field cancerization [28, 45]. 
Table 3 Summary of management for patients with AK

\section{Comments}

Patient considerations

Medical comorbidities

Likelihood of adherence

Seeking single treatment

Financial capabilities

Lesion characteristics

Number

Thin vs. hyperkeratotic

Low number: amenable to destructive therapy; high number: requires field therapy

Hyperkeratotic: may require debridement before destructive treatment; biopsy should be considered when hyperkeratotic

Location Facial lesions: well treated by field pharmacotherapies

Backs of hands: more difficult to treat

Use special care for high-risk locations such as periorbital area, lips, and below knee

Therapeutic considerations

Destructive modalities

Cryosurgery

Most common because of ease of use good tolerability, efficacy for thin lesions

Shave excision

Consider for single recurrent lesion

Curettage

Invasive; requires medical prophylaxis; not first-choice treatment for $\mathrm{AK}$

Dermabrasion and

chemical peels

Topical pharmacotherapy

5-fluorouracil

Frequently used

Multiple concentrations available

Intensity of localized skin reaction may limit tolerability in some patients

Imiquimod

Diclofenac

Ingenol mebutate

Convenient: very short duration of treatment (2-3 days)

Photodynamic therapy

Higher cost; requires specialized equipment

Patient education

Counseling from dermatology clinical team should include

Nature of disease

Proper use of treatments

Expectations of treatments

Use of sunscreens

Skin self-examinations

Reproduced with permission from Ceilley and Jorizzo [20]

$A K$ actinic keratosis 


\section{New Treatments}

The use of daylight PDT along with a suitable sunscreen following methyl aminolevulinate application can minimize pain associated with conventional PDT and may be a convenient alternative in geographical areas where appropriate daylight and weather conditions prevail [46]. An international consensus concluded that daylight PDT is an effective and well-tolerated field therapy, particularly in those patients with large areas affected by AKs that can be exposed to daylight [47], and suggested that this therapy is studied further with regard to appropriate seasonal and time-of-day use in different geographical locations. Experience with daylight PDT in UK, Canada, and Australia primary care is currently minimal.

The advent of new and efficacious topical treatments for $\mathrm{AK}$ has led to the instigation of new guidelines. The National Institute for Health and Care Excellence (NICE) recently published a guide "Actinic Keratosis: Ingenol Mebutate Gel" [48] to update physicians following the approval of ingenol mebutate gel in the UK. The publication concluded that ingenol mebutate gel had similar efficacy to other field-directed treatment therapies, but with much shorter treatment duration; however, side effects between the therapies varied. The most common side effects for ingenol mebutate gel were skin responses at application site. In addition, the Scottish Medicines Consortium completed an assessment on ingenol mebutate gel in February 2013, and concluded that in the four randomized, double-blind, phase III studies, a significantly greater proportion of adults with AK achieved complete clearance when treated with ingenol mebutate gel [49]. Furthermore, a 2012 Cochrane Database Systematic Review of 83 randomized controlled trials $(n=10,036)$ of the management of $\mathrm{AK}$ concluded that for individual lesions, PDT appeared more effective and had increasing reports of a better cosmetic outcome than cryosurgery [15]. For field-directed treatments, diclofenac, 5-FU, imiquimod, and ingenol mebutate gel had similar efficacy, but their associated side effect and cosmetic outcomes were different [15]. The authors conclude that direct head-to-head studies of these treatments are required to determine the optimal therapeutic approach for AK.

\section{Management and Healthcare}

\section{Australia}

Primary care physicians have a pivotal position in the Australian health care system, as they diagnose and manage a greater number of skin lesions as well as more serious ones, particularly in rural areas. However, 9\% of AK cases are referred to non-dermatological specialists, of which $57 \%$ are then referred to a dermatologist [44].

In Australia, although cryosurgery is subsidized for the general public, not all field therapies are, except for repatriated patients. Imiquimod is only subsidized for superficial basal cell carcinoma that is not amenable to surgery. There are some subsidies available for AK treatment depending on patient health care cover. Patients are not currently subsidized for newer treatments such as non-surgical or specialist treatments (e.g., PDT, both conventional or daylight). The availability of subsidies is likely to influence treatment choice, particularly if the patient has many lesions. In accordance with the current Australian health care system fee schedule, treatment of SCC in situ attracts a fee [25], as does both cryosurgery for more than 10 AK lesions, and curettage/excision of an AK. Consequently, cost 
The primary aim of treatment of AK is to reduce the total number of lesions that the patient has at any one time. The fewer lesions a patient has the less risk they have for developing an SCC.

\section{Diagnosis}

- Examine skin thoroughly for more serious sun-related skin tumors

- Provide information on UV protection (including the need

to wear a hat), vitamin $D$, and $A K$

- Use of a moisturiser 2-3 times a day can help differentiate

between early AK and dry scaly areas of normal skin

- Examine frequently: once patients start to develop AK they

will almost certainly develop more

- Educate patients about which skin changes need to be

reported, eg unfamiliar skin lesions. Transformation into an

SCC may be suggested by recent growth, discomfort,

ulceration, or bleeding

Refer to GPwSI or specialist dermatologist

- Diagnostic uncertainty

- Immunosuppressed patients

- Very young patients (consider xeroderma pigmentosum)

- Suspicion of SCC (recent growth/pain/bleeding,

elevation, ulceration, induration, tenderness surrounding

inflammation)

Lesion evaluation and observation

Not all patients need treating, eg patients with smaller numbers of lesions, especially if they have a reduced life expectancy.

Such patients should be given a choice about whether to receive treatment

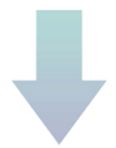


is also a factor in treatment choice for the patient.

\section{$U K$}

Prescription charges apply in the UK for the majority of the adult population (16-60 years of age). However, most patients with AK will be exempt from payment because of their age. In the UK, primary care physicians act as the gatekeepers to access specialist services. They see patients presenting with $\mathrm{AK}$ and refer them principally to dermatologists. A UK study in 2005 reported that confirming diagnosis (39\%) and management (57\%) are the primary reasons to refer patients to a specialist [50].

Clinical Commissioning Groups are responsible for the total expenditure resulting from primary care, including referral to secondary care. One of their roles is to reduce referrals. A simple to use treatment for $\mathrm{AK}$, along with further education for general practitioners to increase their diagnosis skills, is likely to be very attractive as it will reduce referral rates.

\section{Canada}

In Canada, primary care physicians play a vital role in reducing the overall burden of $\mathrm{AK}$ through diagnosis and management. Resistant and difficult to treat cases are referred to dermatologists; however, no exact national referral rates have been documented in current literature. The national Pharmacare program subsidizes cryosurgery, with the patient paying either individually or through extended thirdparty insurance for the remaining AK treatment options. The treatment option most often used in Canada for the management of AKs is cryosurgery followed by topical 5-FU. However, patients who have extended insurance now opt for ingenol mebutate because it is convenient to use due to its shorter treatment duration, and also for field treatment of subclinical AK lesions that are not identified and treated with cryosurgery.

\section{CONCLUSION}

The most important reason to identify and treat $\mathrm{AK}$ correctly is to reduce the incidence and burden of cutaneous SCC. There is therefore a need to increase awareness and knowledge about AK, including symptoms, prevention, and its associated risk of non-melanoma skin cancer, especially among the public. Primary care physicians are perfectly placed to convey this message to their patients and play a pivotal role in educating them on the importance of AK treatment and its role in disease progression.

For AK treatment to be successful, physicians and patients should agree on a treatment plan. The physician should be mindful of patient expectations and ensure patient understanding of the treatment and its possible side effects, consequently improving overall adherence. Because of the recurrent nature of $\mathrm{AK}$, patients should maintain an ongoing dialog with their primary care physician or their dermatologist.

Better use of sun-protective products, increased awareness of sun-induced damage, and improved dermatologic screening and treatment can help reduce the harmful effects of chronic sun exposure, and help to prevent malignant transformation and progression to non-melanoma skin cancers.

\section{ACKNOWLEDGMENTS}

Selected images are published with permission from the New Zealand Dermatological Society Incorporated. Scientific support was provided by John R. Zibert, employee of LEO Pharma A/S. Medical writing services were provided by 
Isabelle Leach, Rasila Vaghjiani and Barbara Francis of iMed Comms, Macclesfield, UK, and were funded by LEO Pharma A/S. Article processing charges were funded by LEO Pharma A/S. All named authors meet the International Committee of Medical Journal Editors (ICMJE) criteria for authorship for this manuscript, take responsibility for the integrity of the work as a whole, and have given final approval for the version to be published.

Conflict of interest. Praven Chetty reports no conflicts of interest. Felix Choi has received honoraria from LEO Pharma A/S for speaking engagements. Timothy Mitchell has received honoraria from LEO Pharma A/S for consulting at advisory boards.

Compliance with ethics guidelines. The analysis in this article is based on previously conducted studies, and does not involve any new studies of human or animal subjects performed by any of the authors.

Open Access. This article is distributed under the terms of the Creative Commons Attribution Noncommercial License which permits any noncommercial use, distribution, and reproduction in any medium, provided the original author(s) and the source are credited.

\section{REFERENCES}

1. Uhlenhake EE. Optimal treatment of actinic keratoses. Clin Interv Aging. 2013;8:29-35.

2. Schmitt JV, Miot HA. Actinic keratosis: a clinical and epidemiological revision. An Bras Dermatol. 2012;87:425-34.

3. Harvey I, Frankel S, Marks R, Shalom D, NolanFarrell M. Non-melanoma skin cancer and solar keratoses II analytical results of the South Wales Skin Cancer Study. Br J Cancer. 1996;74:1308-12.
4. Moy RL. Clinical presentation of actinic keratoses and squamous cell carcinoma. J Am Acad Dermatol. 2000;42:S8-10.

5. Glogau RG. The risk of progression to invasive disease. J Am Acad Dermatol. 2000;42:23-4.

6. Rigel DS. Stein Gold LF. The importance of early diagnosis and treatment of actinic keratosis. J Am Acad Dermatol. 2013;68(Suppl 1):S20-7.

7. Rosen T, Lebwohl MG. Prevalence and awareness of actinic keratosis: barriers and opportunities. J Am Acad Dermatol. 2013;68:S2-9.

8. Berger DS, Urbach F. A climatology of sunburning ultraviolet radiation. Photochem Photobiol. 1982;35:187-92.

9. Nestor MS, Zarraga MB. The incidence of nonmelanoma skin cancers and actinic keratoses in South Florida. J Clin Aesthet Dermatol. 2012;5:20-4.

10. Marks R. Freckles, moles, melanoma and the ozone layer: a tale of the relationship between humans and their environment. Med J Aust. 1989;151:611-3.

11. de Berker D, McGregor JM, Hughes BR. Guidelines for the management of actinic keratoses. $\mathrm{Br} \mathrm{J}$ Dermatol. 2007;156:222-30.

12. Babilas $P$, Landthaler $M$, Szeimies RM. Actinic keratoses. Hautarzt. 2003;54:551-60.

13. Salasche SJ. Epidemiology of actinic keratoses and squamous cell carcinoma. J Am Acad Dermatol. 2000;42:4-7.

14. Memon AA, Tomenson JA, Bothwell J, Friedmann PS. Prevalence of solar damage and actinic keratosis in a Merseyside population. $\mathrm{Br} \mathrm{J}$ Dermatol. 2000;142:1154-9.

15. Gupta AK, Paquet M, Villanueva E, Brintnell W. Interventions for actinic keratoses. Cochrane Database Syst Rev. 2012;12:CD004415.

16. Karia PS, Han J, Schmults CD. Cutaneous squamous cell carcinoma: estimated incidence of disease, nodal metastasis, and deaths from disease in the United States, 2012. J Am Acad Dermatol. 2013;68:957-66.

17. MacKie RM. Awareness, knowledge and attitudes to basal cell carcinoma and actinic keratoses among the general public within Europe. J Eur Acad Dermatol Venereol. 2004;18:552-5.

18. Halpern AC, Hanson LJ. Awareness of, knowledge of and attitudes to nonmelanoma skin cancer 
(NMSC) and actinic keratosis (AK) among physicians. Int J Dermatol. 2004;43:638-42.

19. The Lewin Group Inc. for The Society for Investigative Dermatology and The American Academy of Dermatology Association. The burden of skin diseases. Available from: http://www.lewin.com/ / media/Lewin/Site_Sections/Publications/april2005 skindisease.pdf. Last accessed April 22, 2013.

20. Ceilley RI, Jorizzo JL. Current issues in the management of actinic keratosis. J Am Acad Dermatol. 2013;68(Suppl 1):S28-38.

21. Naylor MF, Boyd A, Smith DW, Cameron GS, Hubbard D, Neldner KH. High sun protection factor sunscreens in the suppression of actinic neoplasia. Arch Dermatol. 1995;131:170-5.

22. Thompson SC, Jolley D, Marks R. Reduction of solar keratoses by regular sunscreen use. N Engl J Med. 1993;329:1147-51.

23. van der Pols JC, Williams GM, Pandeya N, Logan V, Green AC. Prolonged prevention of squamous cell carcinoma of the skin by regular sunscreen use. Cancer Epidemiol Biomark Prev. 2006;15:2546-8.

24. Stockfleth E, Ferrandiz C, Grob JJ, Leigh I, Pehamberger H, Kerl H. Development of a treatment algorithm for actinic keratoses: a European Consensus. Eur J Dermatol. 2008;18:651-9.

25. Reeve T. Cancer Council Australia 2008 Clinical Practice Guide Basal cell carcinoma, squamous cell carcinoma (and related lesions): a guide to clinical management in Australia. Available from: http:// www.cancer.org.au/content/pdf/HealthProfessiona 1s/ClinicalGuidelines/Basal_cell_carcinoma_Squam ous_cell_carcinoma_Guide_Nov_2008-Final_with_ Corrigendums.pdf. Last accessed Nov 8, 2013.

26. Schumack PS. Australian Prescriber: non-surgical treatments for skin cancer. Available from: http:// www.australianprescriber.com/magazine/34/1/6/7. Last accessed Nov 8, 2013.

27. Chia A, Moreno G, Lim A, Shumack S. Actinic keratoses. Aust Fam Physician. 2007;36:539-43.

28. Sterry W. European Dermatology Forum Guideline on Actinic Keratosis. Available from: http://www. ensas.ee/docs/management_of_actinic_keratoses. pdf. Last accessed Nov 8, 2013.

29. Pharmaderm. Solaraze gel. Prescribing information. Available from: http://www.accessdata.fda.gov/ drugsatfda_docs/label/2011/021005s013lbl.pdf. Last accessed April 10, 2014.

30. Jenerowicz D, Jabubowicz O, Polanska A, Sadowska A, Danczak-Pazdrowska A, Zaba R. Photosensitivity to selected topical nonsteroidal anti-inflammatory drugs preparations-a review of literature data and author's own experience. Cent Eur J Immunol. 2013;36:197-203.

31. Electronic Medicines Consortium (eMC). Solaraze SmPC. Available from: http://www.medicines.org. uk/emc/medicine/21229/SPC. Last accessed April 10, 2014.

32. 3M Health Care Limited. Aldara (Imiquimod): Highlights of prescribing information. Available from: http://www.accessdata.fda.gov/drugsatfda docs/label/2007/020723s020lbl.pdf. Last accessed June 4, 2014.

33. Stockfleth E, Sterry W, Carey-Yard M, Bichel J. Multicentre, open-label study using imiquimod 5\% cream in one or two 4-week courses of treatment for multiple actinic keratoses on the head. $\mathrm{Br} J$ Dermatol. 2007;157(Suppl 2):41-6.

34. Jorizzo JL, Markowitz O, Lebwohl MG, et al. A randomized, double-blinded, placebo-controlled, multicenter, efficacy and safety study of $3.75 \%$ imiquimod cream following cryosurgery for the treatment of actinic keratoses. J Drugs Dermatol. 2010;9:1101-8.

35. Martin G, Swanson N. Clinical findings using ingenol mebutate gel to treat actinic keratoses. J Am Acad Dermatol. 2013;68(1 Suppl 1):S39-48.

36. Lebwohl M, Swanson N, Anderson LL, Melgaard A, $\mathrm{Xu} \mathrm{Z}$, Berman B. Ingenol mebutate gel for actinic keratosis. N Engl J Med. 2012;366:1010-9.

37. Lebwohl M, Shumack S, Gold LS, Melgaard A, Larsson T, Tyring SK. Long-term follow-up study of ingenol mebutate gel for the treatment of actinic keratoses. JAMA Dermatol. 2013;149:666-70.

38. Dosik JS, Damstra M, Udell C, Welburn P. Evaluation of the skin sensitization, photoirritation, and photoallergic potential of ingenol mebutate gel in healthy volunteers. J Clin Aesthet Dermatol. 2014;7:35-42.

39. Berman B, Goldenberg G, Hanke W, et al. Efficacy and safety of ingenol mebutate $0.015 \%$ gel 3 weeks after cryosurgery of actinic keratosis: 11-week results. J Drugs Dermatol. 2014;13:154-60.

40. Berman B, Goldenberg G, Hanke CW, et al. Efficacy and safety of ingenol mebutate $0.015 \%$ gel after cryosurgery of actinic keratosis: 12-month results. J Drugs Dermatol. 2014;13:741-7.

41. Wolf JE Jr, Rigel DS. Understanding efficacy endpoints in studies of field-directed therapy for actinic keratosis. Int J Dermatol. 2013;52:1063-70. 
42. Garside R, Pearson M, Moxham T. What influences the uptake of information to prevent skin cancer? A systematic review and synthesis of qualitative research. Health Educ Res. 2010;25:162-82.

43. Tran DT, Salmon R. Field treatment of facial and scalp actinic keratoses with photodynamic therapy: survey of patient perceptions of treatment satisfaction and outcomes. Australas J Dermatol. 2011;52:195-201.

44. Streeton CL, Gospodarevskaya E, Harris AH. How are solar keratoses treated by general practitioners in Australia? Int J Dermatol. 2006;45:272-6.

45. Primary Care Dermatology Society. Actinic keratosis (syn. solar keratosis). Available from: http://www.pcds.org.uk/clinical-guidance/actinickeratosis-syn.-solar-keratosis. Last accessed April 17, 2014.

46. Morton CA, Szeimies RM, Sidoroff A, Braathen LR. European guidelines for topical photodynamic therapy part 1: treatment delivery and current indications-actinic keratoses, Bowen's disease, basal cell carcinoma. J Eur Acad Dermatol Venereol. 2013;27:536-44.
47. Wiegell SR, Wulf HC, Szeimies RM, et al. Daylight photodynamic therapy for actinic keratosis: an international consensus: International Society for Photodynamic Therapy in Dermatology. J Eur Acad Dermatol Venereol. 2012;26:673-9.

48. National Institute for Health and Care Excellence (NICE). Actinic keratosis ingenol mebutate gel. Available from: http://www.nice.org.uk/advice/ esnm14. Last accessed Jan 20, 2014.

49. Scottish Medicines Consortium. Briefing note: ingenol mebutate gel (Picato). Available from: http://www.scottishmedicines.org.uk/SMC_Advice/ Advice/851_13_ingenol_mebutate_gel_Picato/Briefi ng_note_ingenol_mebutate_gel_Picato. Last accessed April 11, 2014.

50. AmirthaVani BP, Charles-Holmes R, Humphreys F, Bedlow AJ, Gee BC, Benjamin M. Evaluation of the dermatology outpatient service: a general practitioners' questionnaire survey about the quality of outpatient consultations. Br J Dermatol. 2005;153:44-5. 